\title{
Response to Discussion of "A Modular Speed-Drooped System for High Reliability Integrated Modular Motor Drives"
}

\author{
A. Galassini*, A. Costabeber*, M. Degano*, G. Buticchi ${ }^{+}$, C. Gerada*+ $^{*+}$ \\ Power Electronic Machine Control Group (PEMC) \\ The University of Nottingham \\ ${ }^{*}$ United Kingdom, ${ }^{+}$China
}

\author{
D. Barater \\ Department of Engineering Enzo Ferrari \\ University of Modena and Reggio Emilia \\ Italy
}

The authors appreciate the interest shown in our paper. In the paper under discussion [1], a distributed speed control strategy suitable for multi-three-phase machines with enhanced power sharing capability is presented. The focus of the manuscript is on the power sharing transient controllability achieved by using a sharing regulator based on the droop controller, which was introduced for the first time by Fingas and Lehn [2]. In [1], the authors added the outermost loop in charge of restoring the drooped output speed. The overall control strategy and the design procedure of each loop current, sharing, and speed - is presented and validated by means of experimental results. Two off-the-shelf three-phase induction machines coupled on the same shaft and controlled by a custom inverter were loaded by a third off-the-shelf threephase induction machine.

A similar control strategy has been validated by the same main author on a multi-three-phase two pole wound field synchronous generator with nine phases [3]. The difference is in the nature of both the electro-magnetic and mechanical couplings. Indeed, whilst in [1] there is no electro-magnetic coupling between the stators of the two induction motors and the mechanical coupling is elastic, in [3] is the opposite. Mutual electro-magnetic interactions among different sets of windings within the stator are present and, since there is only one rotor, the mechanical coupling is rigid.
The same as in [1], the speed loops in [3] were coded on a single control platform for simplicity. In [1], a custom control platform developed by the PEMC (Power Electronics Machine and Control) group at The University of Nottingham, UK presented in [4], Fig. 3 - was used. In [3], a newer custom control platform name $u$ Cube [5] and developed by the same group was used.

The authors acknowledge the point rose by the discussion. When coding three loops on the same controller, the delay on the measured speeds is not taken into account and the modules should not be defined independent. Actually, also the switching modulators are synchronised when the paralleled loops are coded on the same control platform. Higher 0sequence ripple by switching the two paralleled converters out-of-phase by $\pi[\mathrm{rad}]$ was demonstrated by Fingas and Lehn [2]. Nevertheless, programming, flashing, and debugging three fully independent system would take much longer to validate whichever novel control strategy. Whilst out-phase-modulators can be avoided by synchronising the clocks of the independent Micro-Controller-Units (MCUs), delays on the measured speeds could be taken into account by considering the speed measurement biases in addition to the control schematic from the paper under discussion [1].

The authors arising this discussion based their study on the schematic shown in Fig. 1, which has been taken from

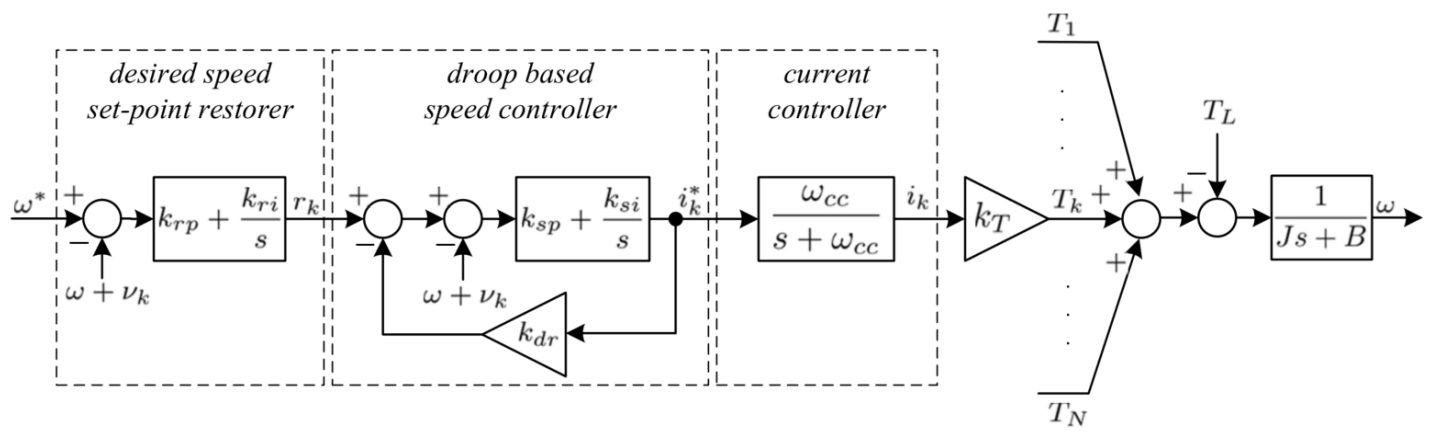

Fig. 1. Wrong control schematic taken from [6], [7]. In the paper under discussion [1], $k_{s p}$ is not present. 


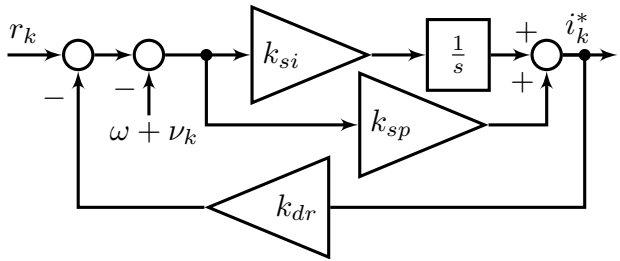

(a) Droop coefficient and PI controller like in [6], [7]

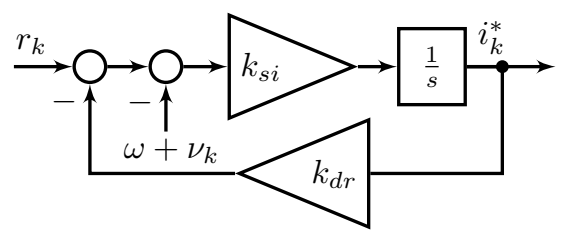

(b) Droop coefficient and I controller like in [1]

Fig. 2. Proportional Integral vs Integral controller

[6], [7], where a Proportional Integral (PI) controller was used. For better clarity, the PI controller together with the droop coefficient $k_{d r}$ is shown in Fig. 2a. On the other hand, in [1], the Proportional gain $k_{s p}$ was discarded leading to a simpler control schematic shown in Fig. 2b. By setting to zero $k_{s p}$ in Fig. 2a, the power sharing transient can be effectively controlled and its time constant can be predicted. The respective transfer functions of regulators shown in Fig. 2 are the followings:

$$
\begin{gathered}
G_{W}(s)=\frac{s k_{s p}+k_{s i}}{s\left(1+k_{s p} k_{d r}\right)+k_{s i} k_{d r}} \\
G_{R}(s)=\frac{k_{s i}}{s+k_{s i} k_{d r}}
\end{gathered}
$$

which for $s \rightarrow 0$ are leading both to the following steady state value:

$$
G_{R}(s \rightarrow 0)=G_{W}(s \rightarrow 0)=\frac{1}{k_{d r}}
$$

On the other hand, the initial values are different:

$$
\begin{gathered}
G_{W}(s \rightarrow \infty)=\frac{k_{s p}}{1+k_{s p} k_{d r}} \\
G_{R}(s \rightarrow \infty)=0
\end{gathered}
$$

Assuming $k_{d r}=0.2, k_{s i}=100, k_{s p}=10$, both the Bode plots of (1) and (2) are shown in Fig. 3, and looking at the respective step responses shown in Fig. 4, steady state and initial values described by Eqs. (3)-(5) can be verified.

We hope the above discussion clarified the controllability of power sharing transients by setting to 0 the proportional gain $k_{s p}$. In general, the measured speed delay $\nu_{k}$ should be taken into account. However, depending on how the system is implemented, delays could be very different. Considering the Integrate Modular Motor Drive application, we believe that until every single module is implemented by using the same transducers, the system stability will not be affected. In the future, by increasing the Technology Readiness Level (TRL), every module will be implemented on its own MCU and the

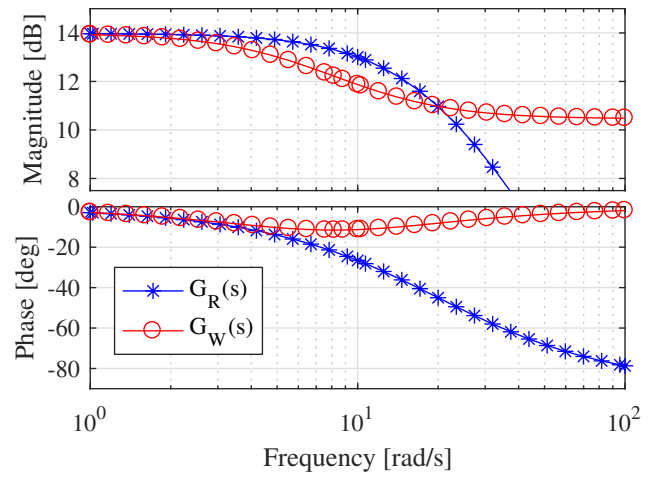

Fig. 3. Bode plots of controllers $G_{R}(s)$ (Fig. 2b) and $G_{W}(s)$ (Fig. 2a)

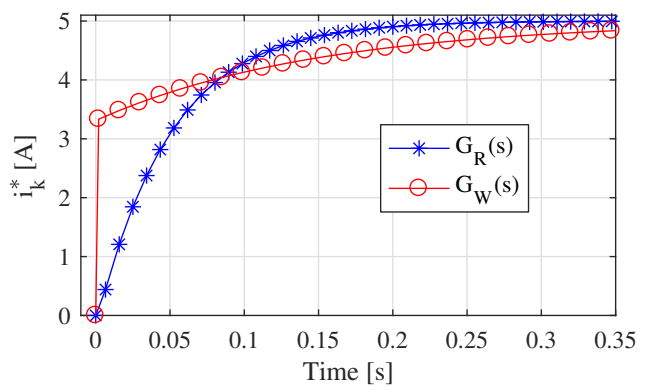

Fig. 4. Step response of controllers $G_{R}(s)$ (Fig. 2b) and $G_{W}(s)$ (Fig. 2a).

measured speed delay will be taken into account as well as its impact on the overall system stability.

\section{REFERENCES}

[1] A. Galassini, A. Costabeber, C. Gerada, G. Buticchi, and D. Barater, "A modular speed-drooped system for high reliability integrated modular motor drives," IEEE Transactions on Industry Applications, vol. 52, no. 4, pp. 3124-3132, July 2016.

[2] D. Fingas and P. Lehn, "Operation of parallel three-phase converters as a motor drive," in Industrial Electronics, 2009. IECON '09. 35th Annual Conference of IEEE, Nov 2009, pp. 1217-1222.

[3] A. Galassini, A. Costabeber, C. Gerada, and A. Tessarolo, "Distributed speed control for multi-three phase electrical motors with improved power sharing capability," in 2017 IEEE Energy Conversion Congress and Exposition (ECCE), Oct 2017, pp. 2492-2497.

[4] L. de Lillo, L. Empringham, P. Wheeler, S. Khwan-on, C. Gerada, M. Othman, and X. Huang, "Multiphase power converter drive for fault-tolerant machine development in aerospace applications," Industrial Electronics, IEEE Transactions on, vol. 57, no. 2, pp. 575-583, Feb 2010

[5] A. Galassini, G. L. Calzo, A. Formentini, C. Gerada, P. Zanchetta, and A. Costabeber, "ucube: Control platform for power electronics," in 2017 IEEE Workshop on Electrical Machines Design, Control and Diagnosis (WEMDCD), April 2017, pp. 216-221.

[6] A. Galassini, A. Costabeber, C. Gerada, G. Buticchi, and D. Barater, "State space model of a modular speed-drooped system for high reliability integrated modular motor drives," in Electrical Eystems for Aircraft, Railway, Ship propulsion and road vehicles (ESARS), 2015.

[7] A. Galassini, A. Costabeber, and C. Gerada, "Speed droop control of integrated modular motor drives," in IECON 2015 - 41st Annual Conference of the IEEE Industrial Electronics Society, Nov 2015, pp. $003271-003276$. 